\title{
Enhancing Light Coverage of Photosynthetic Bacteria to Augment Photosynthesis by Conjugated Polymer Nanoparticles
}

Zijuan Wang,,${ }^{1,2}$ Dong Gao, ${ }^{2}$ Yong Zhan ${ }^{2}$ and Chengfen Xing ${ }^{* 1,2}$

1 School of Materials Science and Engineering, Hebei University of Technology, Tianjin 300130 (P.R. China)

2 Key Laboratory of Hebei Province for Molecular Biophysics, Institute of Biophysics, Hebei University of Technology, Hebei University of Technology, Tianjin 300130 (P.R. China)

E-mail: xingc@hebut.edu.cn 


\section{Materials}

Three typical conjugated polymers (P1, P2, P3) were synthesized according to previous literature. ${ }^{1,2}$ R. palustris (AS1.2352) was purchased from Beijin BeNa Culture Co., Ltd. (China). Bacterial penetrating peptides TAT (RKKRRQRRRC) was synthetized by Zhejiang Ontores Biotechnologies Co., Ltd. (China). DSPE-PEG2000-Mal was synthetized by Shanghai ponsure Biotechnologies Co., Ltd. (China). ATP Assay Kit was purchased from Beyotime Biotechnology (China). All other chemicals were purchased from Aladdin, Sigma and used as received.

\section{Instruments}

UV-Vis absorption spectra were measured on a SPECORD 250 PLUS (GERMANY). Fluorescence spectra were measured on a Hitachi F-4600 fluorescence spectrophotometer (JAPAN). Dynamic light scattering (DLS) and Zeta potentials were carried out through a Malvern Nano-ZS90 (UK). Fluorescence images were taken by a Leica TCS SP5 confocal laser scanning microscope (GERMANY). The irradiation source of visible light was used from MEJIRO GENOSSEN MVL-210 (JAPAN). SEM images were performed on an emission scanning electron microscope of NOVA NANOSEM450 (USA). TEM images were taken on Hitachi Model HT7700 120kV Compact-Digital Biological TEM (JAPAN). Fluorescence lifetime was measured on Edinburgh Instruments FS5 (UK). Photosynthetic activity of R. Palustris was measured on Hansatech FMS-2 Pulse Modulated Fluorometer (UK). ATP production was measured on a Molecular Devices SpectraMax i3 (USA).

\section{Preparation of CPNs-TAT}

CPNs were prepared by co-precipitation method. To obtain CPNs, $0.2 \mathrm{mg}$ CPs and $5.0 \mathrm{mg}$ DSPE-PEG ${ }_{2000}-$ Mal were dissolved in $1 \mathrm{~mL}$ THF. Then the above THF solution was added to $9 \mathrm{~mL}$ ultrapure water under ultrasound. Subsequently, the mixture was stirred in the fume hood overnight, and then filtered with $0.22 \mu \mathrm{m}$ syringe driven filter. The filtrate was then added to the phosphate solution of TAT peptide $(0.44 \mathrm{mM})$ and the solution was stirred at room temperature for 4 hours. Finally, the CPNs-TAT was centrifuged with a $100 \mathrm{kDa}$ ultrafiltration tube to remove the unreacted peptide. 


\section{Agarose gel electrophoresis}

$0.2 \mathrm{~g}$ agarose was fully dissolved in $20 \mathrm{ml} 1 \times \mathrm{TAE}$ buffer under microwave oven. After cooling to $60 \sim 70{ }^{\circ} \mathrm{C}$, the comb and baffle were set in mold. Until the gel curing, the baffles was removed and placed into the electrophoresis tank to make sure the gel completely soaked in TAE buffer. Then the comb was vertically pulled out. The CP1Ns and CP1Ns-TAT solution was added to the gel pore in an electrophoresis condition of $110 \mathrm{~V}$ for $25 \mathrm{~min}$. After the electrophoresis, the gel was taken out and placed in the gel imager for imaging.

\section{R. palustris culture}

This strain was grown in 112 Van Niel's Yeast Agar. ${ }^{3} \mathrm{~K}_{2} \mathrm{HPO}_{4} 1.0 \mathrm{~g}, \mathrm{MgSO}_{4} 0.5 \mathrm{~g}$, yeast extract 10.0 $\mathrm{g}$, distilled water $1000 \mathrm{ml}, \mathrm{pH}$ 7.0-7.4. Argon gas was pumped to the medium to exhaust the air and then inoculated culture solution $15 \%(\mathrm{v} / \mathrm{v})$ was added to the $20 \mathrm{ml}$ serum bottle. The cultivation was placed in incubator under anaerobic illumination for 5 days with culture temperature of $30^{\circ} \mathrm{C}$ until the culture solution turns dark red. The optical density at $660 \mathrm{~nm}$ was then used as the biological index in the following experiment. ${ }^{4}$

\section{Preparation of $R$. palustris/CPNs-TAT}

$10 \mathrm{mM}$ PBS buffer suspension of $R$. palustris $\left(\mathrm{OD}_{660}=1.0\right)$ was mixed with CPNs-TAT and CPNs to afford solutions with CPNs-TAT and CPNs concentration of $1,5,10 \mu \mathrm{g} \cdot \mathrm{mL}^{-1}$, and the solution was incubated at room temperature for $30 \mathrm{~min}$. Then, the mixture was centrifuged at $6000 \mathrm{r} \cdot \mathrm{min}^{-1}$ for $10 \mathrm{~min}$ and washed twice with PBS buffer to remove the unbound nanoparticles. All buffers were anaerobic conditions by pumping Ar gas for $30 \mathrm{~min}$ and all the experiments are repeated for three times.

\section{CLSM imaging}

The suspension $(10 \mu \mathrm{L})$ of $R$. palustris/CPNs-TAT and $R$. palustris were taken on the microslide, and covered with coverslip lightly. The laser confocal scanning microscope is used for imaging, and the light field and fluorescence field images of the sample are collected. 


\section{SEM imaging}

The suspension $(10 \mu \mathrm{L})$ of $R$. palustris/CPNs-TAT and $R$. palustris were immobilized overnight in the PBS solution of $0.5 \%$ glutaraldehyde at $4^{\circ} \mathrm{C}$. After the sample was immobilized and washed with PBS buffer for three times, the samples were dehydrated with $20 \%, 40 \%, 50 \%, 70 \%, 90 \%$ and $100 \%$ ethanol gradient every $7 \mathrm{~min}$. Then $2 \mu \mathrm{L}$ liquid was added on the clean silicon sheet and dried naturally, followed by spraying gold on the sample and scanning with electron microscopy.

\section{Measurement of fluorescence lifetime of CPNs-TAT and $R$. palustris/CPNs-TAT}

The suspension of CPNs-TAT with or without $R$. palustris was incubated in PBS buffer solution at room temperature for 30 minutes. The solution was centrifuged to remove supernatant and suspend. Then the suspension was measured on Edinburgh Instruments FS5 with time-correlated single counting mode.

\section{Measurement of fluorescence spectra of the interaction between $R$. palustris and CPNs-TAT}

The suspension $(1 \mathrm{~mL})$ of $R$. palustris/CPNs-TAT was incubated in PBS buffer solution at room temperature for 30 minutes. The solution was centrifuged and the supernatant was discarded. Then the solution was suspended at $4{ }^{\circ} \mathrm{C}$ overnight in $1 \mathrm{ml}$ of $2 \%$ SDS solution. The homogeneous solution was obtained after ultrasonic treatment at room temperature for $30 \mathrm{~min}$. The fluorescence spectra of $R$. palustris/CPNs-TAT were measured. Under the same operating conditions, the sample without TAT was taken as the control.

\section{Measurement of photoreduction rate of $R$. palustris with $\mathrm{K}_{3} \mathrm{Fe}(\mathrm{CN})_{6}$}

For the experimental groups, the suspension $(100 \mu \mathrm{L})$ contained CPNs-TAT $(0,1.0,5.0,10.0$ $\left.\mu \mathrm{g} \cdot \mathrm{mL}^{-1}\right)$ and $R$. palustris $\left(50 \mu \mathrm{L}, \mathrm{OD}_{660}=1.0\right)$ was incubated for $30 \mathrm{~min}$ at room temperature, while the control groups only contains CPNs-TAT. Then, both of the solutions were mixed with $\mathrm{K}_{3} \mathrm{Fe}(\mathrm{CN})_{6}(100$ $\mu \mathrm{L}, 4 \mathrm{mM})$, resulting in a final volume of $200 \mu \mathrm{L}$. The absorbance at $420 \mathrm{~nm}$ was recorded after 0,30 , 
$60,90,120,150$ and $180 \mathrm{~s}$ irradiation with the light intensity of $1,4,8 \mathrm{~mW} \cdot \mathrm{cm}^{-2}$. All the experiments are repeated for three times.

\section{Measurements the photosynthetic activity of $R$. Palustris}

Pulse amplitude modulation (PAM) technology was used to directly measure the photosynthetic activity of $R$. palustris and $R$. palustris/CPNs-TAT. For the experimental groups, the suspension ( $2 \mathrm{~mL})$ contained $5.0 \mu \mathrm{g} \cdot \mathrm{mL}^{-1} \mathrm{CPNs}-\mathrm{TAT}$ and $R$. palustris $(1 \mathrm{~mL}$, OD660 $=1.0)$ was incubated for $30 \mathrm{~min}$ at room temperature, while the control groups only contains $R$. palustris. After light irradiation for 3 min $\left(4 \mathrm{~mW} \cdot \mathrm{cm}^{-2}\right)$, steady $\left(\mathrm{Fs}^{\prime}\right)$, maximum $\left(\mathrm{Fm}^{\prime}\right)$, minimum $\left(\mathrm{Fo}^{\prime}\right)$ and variable state $\left(\mathrm{Fv}^{\prime}, \mathrm{Fv}^{\prime}=\mathrm{Fm}^{\prime}-\mathrm{Fo}^{\prime}\right)$ fluorescence intensity were measured on FMS-2 Pulse Modulated Fluorometer. Electron transport rate (ETR) can be calculated by photosystem operating efficiency $\Phi P S\left(\Phi P S=\left(F m^{\prime}-F s\right) / F m^{\prime}\right)$ and the value of ETR $=\Phi P S \times P D F \times 0.5 \times \alpha\left(\mathrm{PDF}\right.$ is photon flux density which is $200 \mu \mathrm{mol}$ photon $\mathrm{m}^{-2} \mathrm{~s}^{-1}$ here and $\alpha$ is absorptivity coefficient which is 0.84$)$. All the experiments are repeated for three times.

\section{Analysis of ATP synthesis.}

ATP production was measured by ATP biomluminescent Assay Kit (Beyotime Biotechnology). For the experimental groups, the suspension $(100 \mu \mathrm{L})$ contained CPNs-TAT $\left(0,5.0 \mu \mathrm{g} \cdot \mathrm{mL}^{-1}\right)$ and $R$. palustris $\left(50 \mu \mathrm{L}, \mathrm{OD}_{660}=1.0\right)$ was incubated for $30 \mathrm{~min}$ at room temperature, while the control groups only contains CPNs-TAT. Besides, CCCP $(10 \mu \mathrm{M})$ was added in above light irradiation experimental groups and treated the same light irradiation condition to measure ATP production. Moreover ATP production versus time of different groups was also measured. The above experiments were boiled for ATP extraction. All the experiments are repeated for three times.

\section{Growth curves of $R$. palustris and $R$. palustris/CPNs-TAT}

For the experimental groups, the suspension $(2 \mathrm{~mL})$ contained CPNs-TAT $\left(5.0 \mu \mathrm{g} \cdot \mathrm{mL}^{-1}\right)$ and $R$. palustris $(1 \mathrm{~mL}, \mathrm{OD} 660=1.0)$ was incubated for $30 \mathrm{~min}$ at room temperature, while the control groups only contains $R$. palustris. After the unbound CPNs were removed by centrifugation, they were 
suspended into $2 \mathrm{ml}$, and the experimental groups were divided into two groups that treated with and without irradiation for $3 \mathrm{~min}\left(4 \mathrm{~mW} \cdot \mathrm{cm}^{-2}\right)$. After that, each group was inoculated in a $5 \mathrm{~mL}$ headspace bottle. Take $100 \mu \mathrm{L}$ every 12 hours and dilute 5 times to measure the absorbance at $660 \mathrm{~nm}$. All the experiments are repeated for three times. 
a

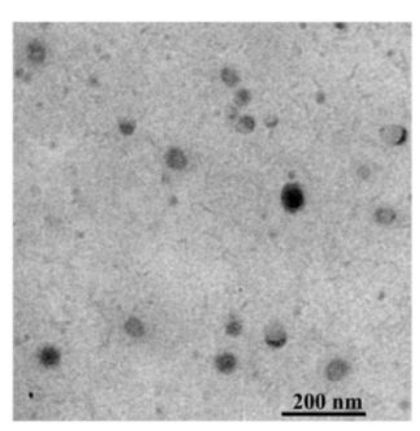

b

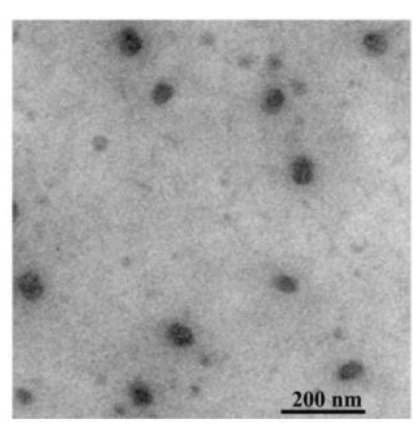

C

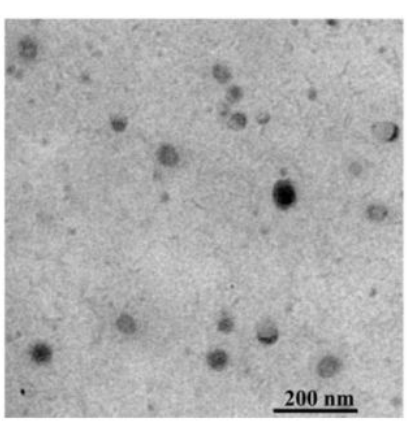

Figure S1. TEM images of (a) CP1Ns-TAT. (b) CP2Ns-TAT. (c) CP3Ns-TAT. [CPNs-TAT] $=5.0 \mu \mathrm{g}$ $\mathrm{mL}^{-1}$
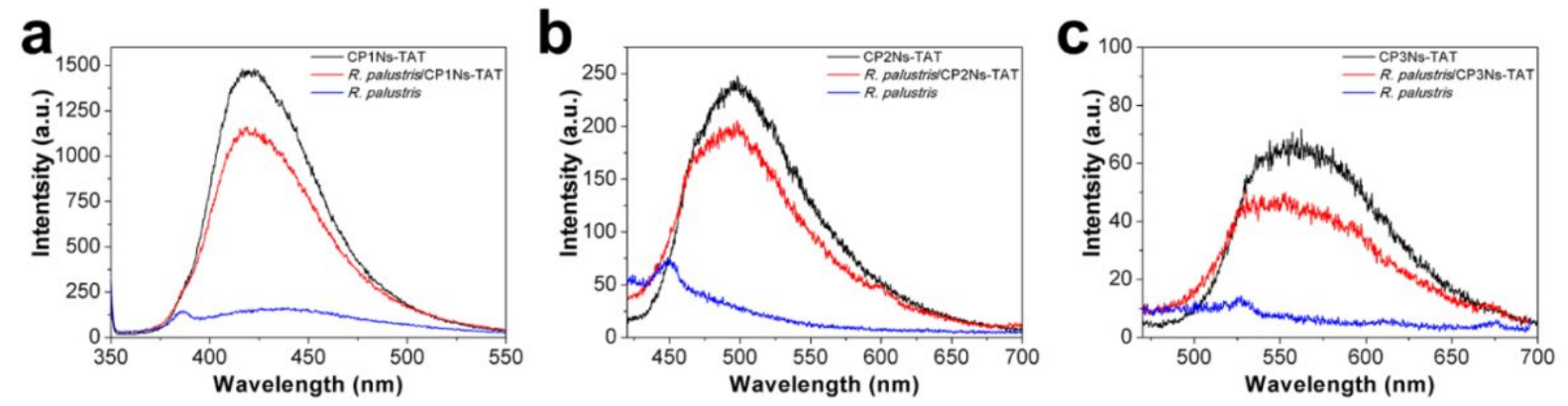

Figure S2. (a) Fluorescence spectra of CP1Ns-TAT, $R$. palustris and $R$. palustris/CP1Ns-TAT. The excitation wavelength is $340 \mathrm{~nm}$. (b) Fluorescence spectra of CP2Ns-TAT, $R$. palustris and $R$. palustris/CP1Ns-TAT. The excitation wavelength is $400 \mathrm{~nm}$. (c) Fluorescence spectra of CP3Ns-TAT, $R$. palustris and $R$. palustris/CP3Ns-TAT. The excitation wavelength is $450 \mathrm{~nm}$. Measurements were performed in PBS buffer solution (10 mM, pH 7.4). [CPNs-TAT] $=5.0 \mu \mathrm{g} \cdot \mathrm{mL}^{-1}$

a

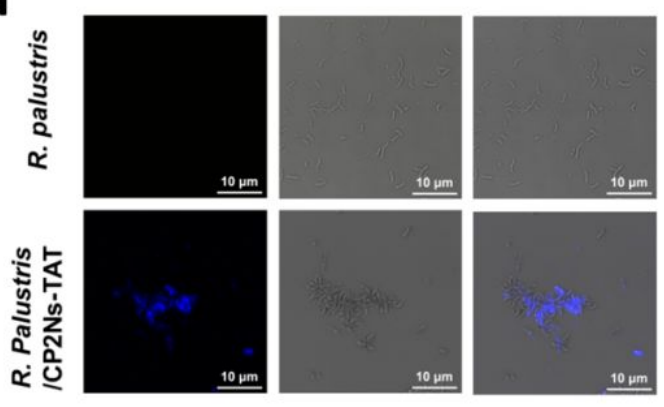

b

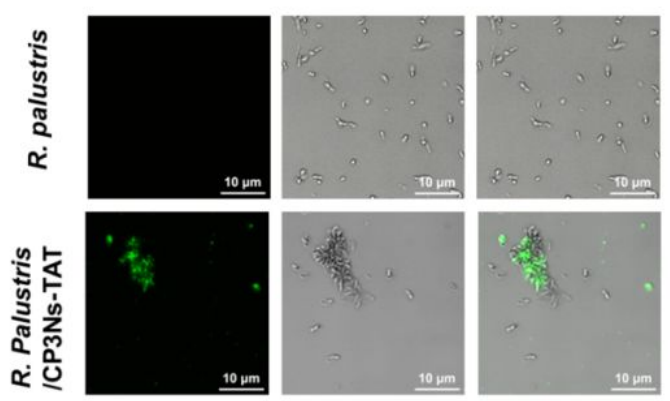

Figure S3. (a) CLSM images of $R$. palustris and $R$. palustris/CP2Ns-TAT. The fluorescence of CP2Ns-TAT is marked blue. (b) CLSM images of $R$. palustris and $R$. palustris/CP3Ns-TAT. The fluorescence of CP3Ns-TAT is marked green. Left: fluorescence images; middle: phase contrast images; right: overlay images. 

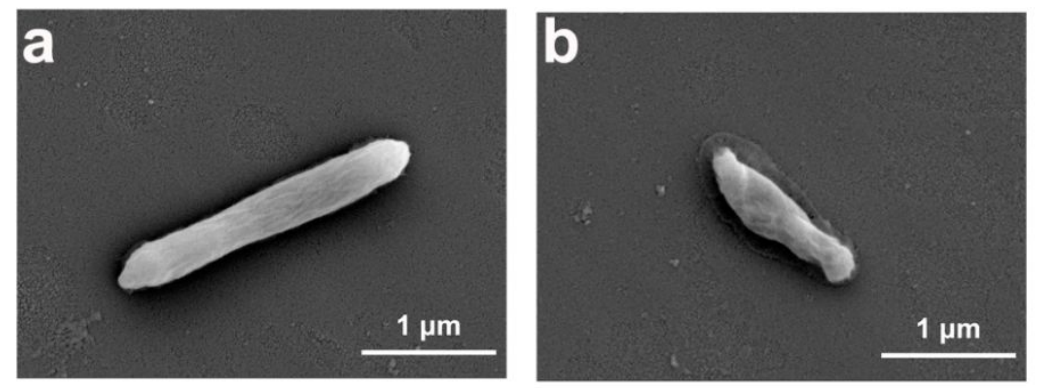

Figure S4. A single bacterium level of (a) $R$. palustris and (b) $R$. palustris/CP2Ns-TAT at an excitation voltage of $5.0 \mathrm{kV}$. (The magnification times is $\times 30000$ ) $[\mathrm{CP} 1 \mathrm{Ns}-\mathrm{TAT}]=5.0 \mu \mathrm{g} \cdot \mathrm{mL}^{-1}$.
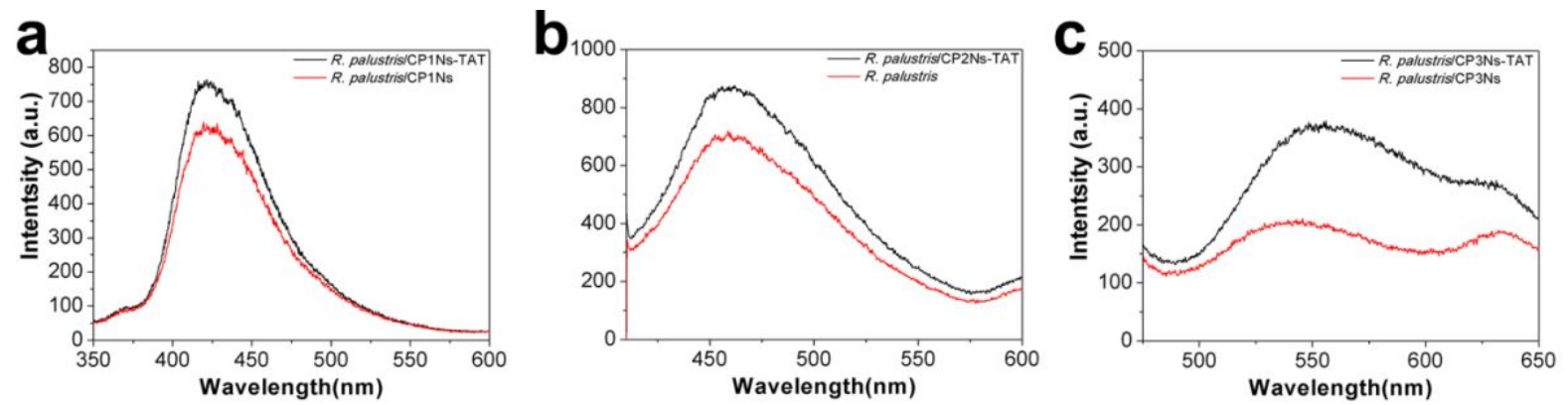

Figure S5. Fluorescence spectra of $R$. palustris/CPNs-TAT and $R$. palustris/CPNs in 2\% SDS. (a) $R$. palustris/CP1Ns-TAT and $R$. palustris/CP1Ns. (b) $R$. palustris/CP2Ns-TAT and $R$. palustris/CP2Ns. (c) $R$. palustris/CP3Ns-TAT and $R$. palustris/CP3Ns. [CPNs-TAT] $=5.0 \mu \mathrm{g} \cdot \mathrm{mL}^{-1}$.
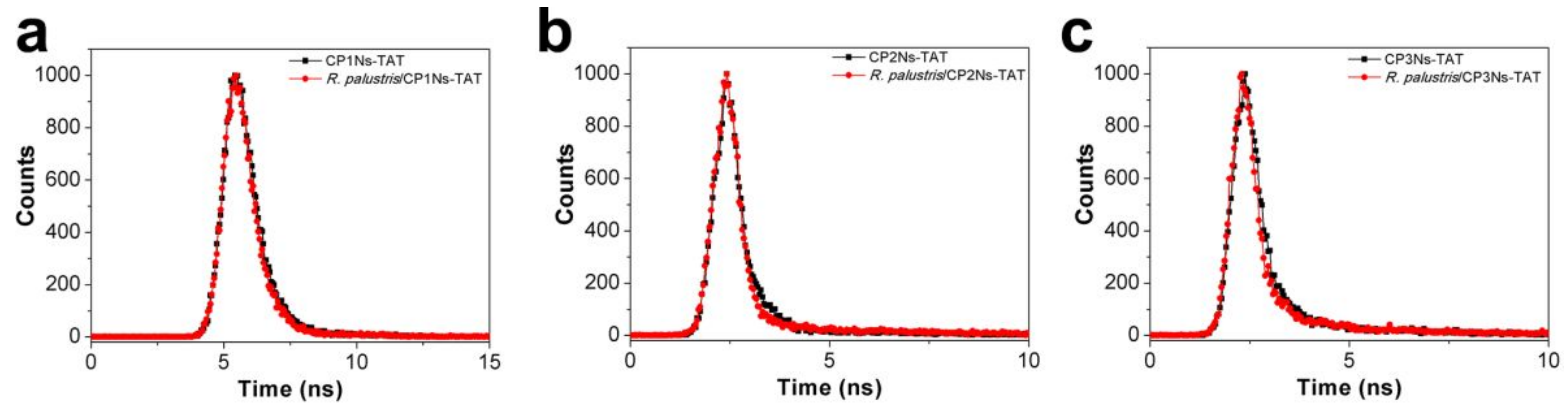

Figure S6. Fluorescence lifetime of CPNs-TAT and $R$. palustris/CPNs-TAT in PBS buffer solution. (a) CP1Ns-TAT and $R$. palustris/CP1Ns-TAT, $\lambda \mathrm{ex}=340 \mathrm{~nm}, \lambda \mathrm{em}=420 \mathrm{~nm}$; (b) CP2Ns-TAT and $R$. palustris/CP2Ns-TAT, CP2Ns-TAT $\lambda \mathrm{ex}=400 \mathrm{~nm}, \lambda \mathrm{em}=500 \mathrm{~nm} ; \quad(\mathrm{c})$ CP3Ns-TAT and $R$. palustris $/ \mathrm{CP} 3 \mathrm{Ns}-\mathrm{TAT}, \lambda \mathrm{ex}=450 \mathrm{~nm}, \lambda \mathrm{em}=550 \mathrm{~nm}$. [CPNs-TAT] $=5.0 \mu \mathrm{g} \cdot \mathrm{mL}^{-1}$. 
Table S1. The $\zeta$ potentials of $R$. palustris and $R$. palustris/CPNs-TAT. Measurement were performed in PBS buffer solution $(10 \mathrm{mM}, \mathrm{pH} 7.4)$ at $25^{\circ} \mathrm{C}$. [CPNs-TAT] $=5.0 \mu \mathrm{g} \cdot \mathrm{mL}^{-1}$. All the experiments are repeated for three times.

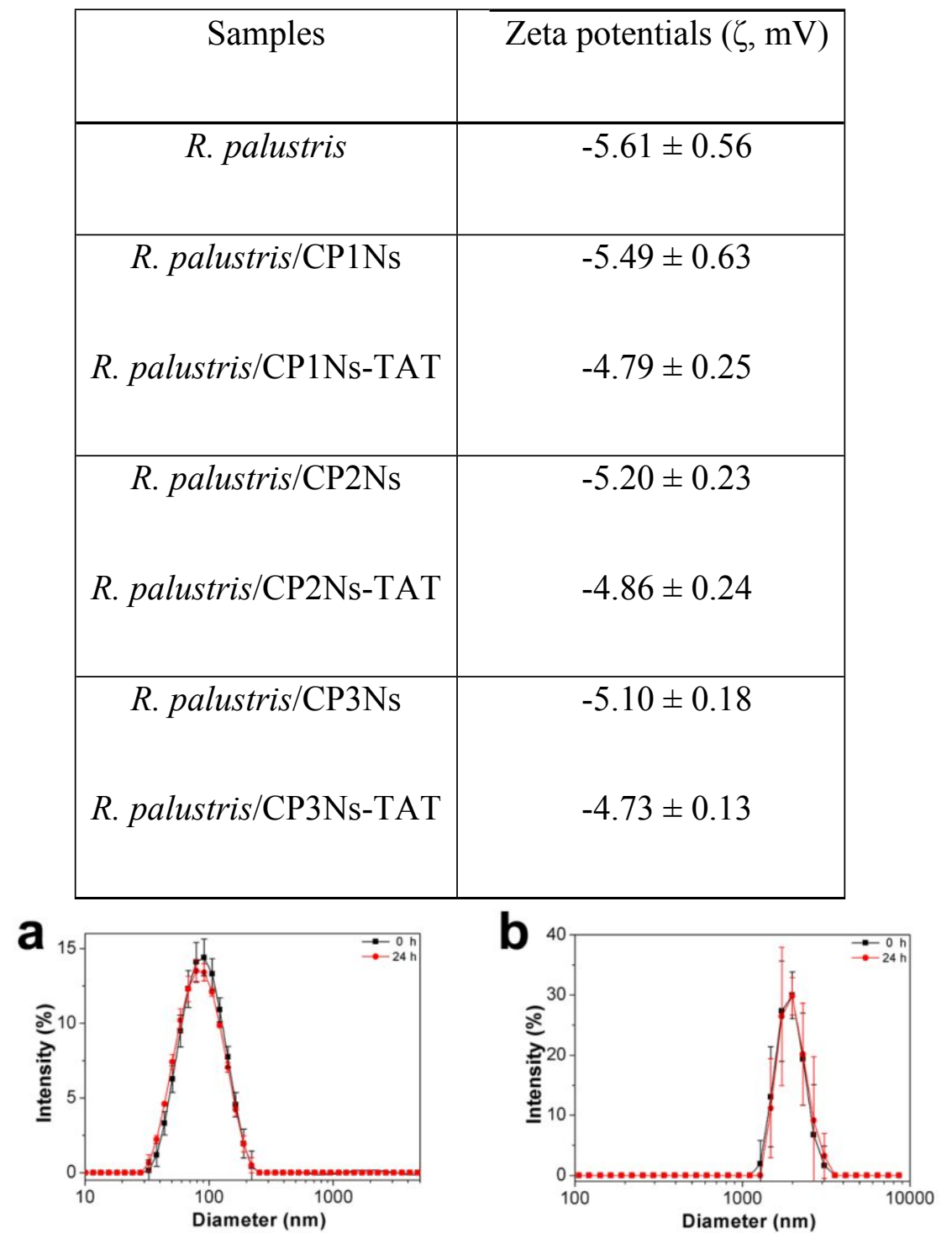

Figure S7. (a) Dynamic light scattering measurement of CP1Ns-TAT before and after $24 \mathrm{~h}$. (b) Dynamic light scattering measurement of $R$. palustris before and after $24 \mathrm{~h}$. Measurement were performed in PBS buffer solution $\left(10 \mathrm{mM}\right.$, pH 7.4) at $25^{\circ} \mathrm{C}$. [CP1Ns-TAT] $=5 \mu \mathrm{g} \cdot \mathrm{mL}^{-1}$. The error bars show the standard deviation of three independent experiments. 


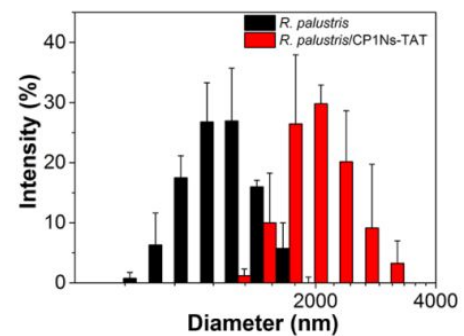

Figure S8. Dynamic light scattering measurement of $R$. palustris incubated with or without CP1Ns-TAT for $24 \mathrm{~h}$. Measurements were performed in PBS buffer solution $(10 \mathrm{mM}, \mathrm{pH} 7.4)$ at $25^{\circ} \mathrm{C}$. $[\mathrm{CP} 1 \mathrm{Ns}-\mathrm{TAT}]=5.0 \mu \mathrm{g} \cdot \mathrm{mL}^{-1}$. The error bars show the standard deviation of three independent experiments.
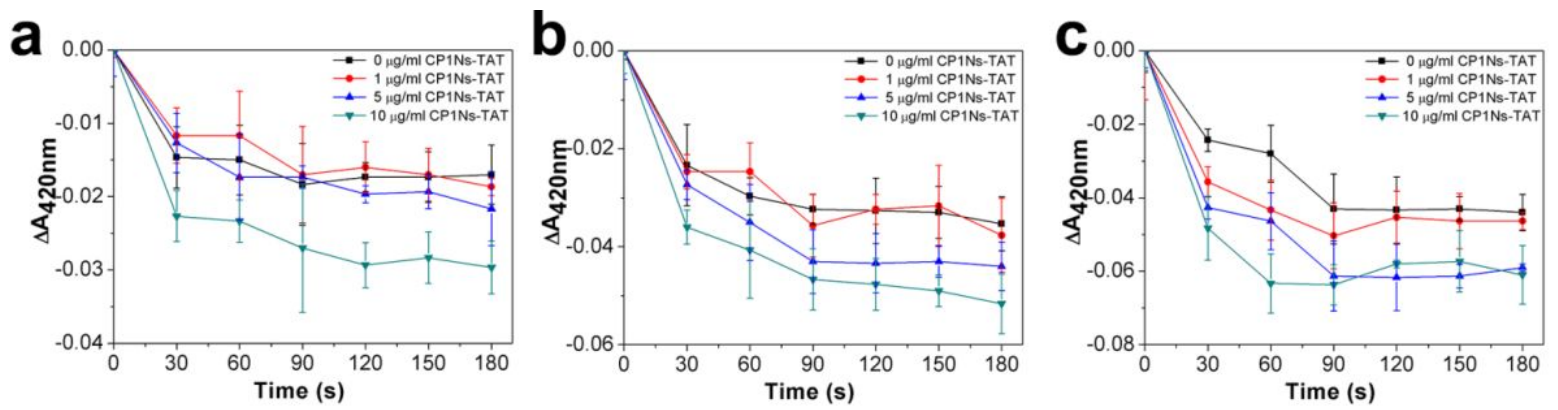

Figure S9. Measurement of photoreduction reaction by $\mathrm{K}_{3}\left[\mathrm{Fe}(\mathrm{CN})_{6}\right]$. Absorption of $R$. palustris and $R$. palustris with different concentrations of CP1Ns-TAT $\left(1.0,5.0,10.0 \mu \mathrm{g} \cdot \mathrm{mL}^{-1}\right)$ at irradiation intensity of (a) $1 \mathrm{~mW} \cdot \mathrm{cm}^{-2}$, (b) $4 \mathrm{~mW} \cdot \mathrm{cm}^{-2}$, (c) $8 \mathrm{~mW} \cdot \mathrm{cm}^{-2}$. [CP1Ns-TAT] $=5.0 \mu \mathrm{g} \cdot \mathrm{mL}^{-1}$. The error bars show the standard deviation of three independent experiments.
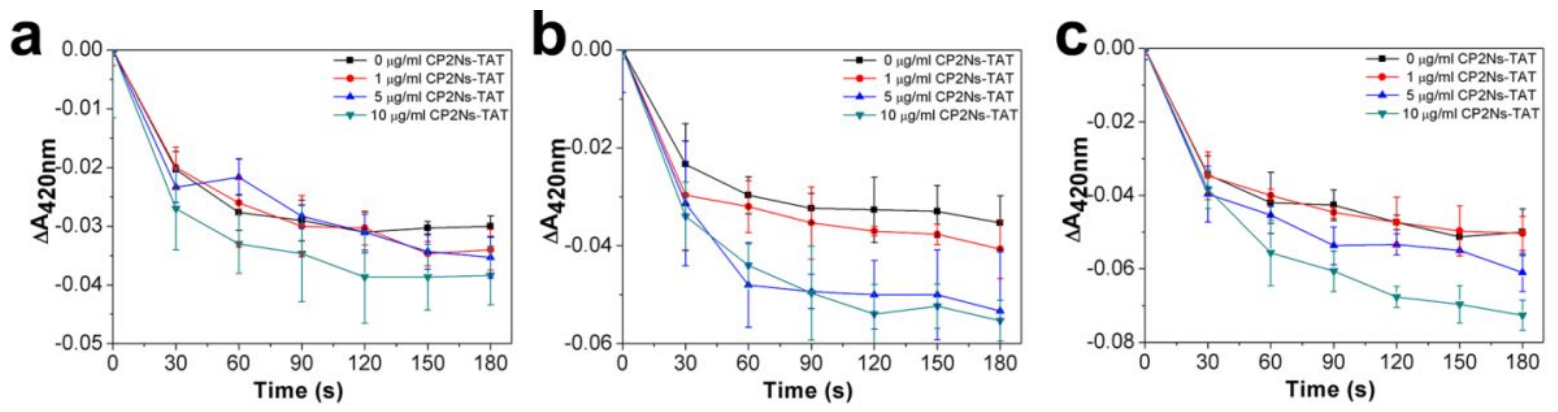

Figure S10. Measurement of photoreduction reaction by $\mathrm{K}_{3}\left[\mathrm{Fe}(\mathrm{CN})_{6}\right]$. Absorption of $R$. palustris and $R$. palustris with different concentrations of CP2Ns-TAT $\left(1.0,5.0,10.0 \mu \mathrm{g} \cdot \mathrm{ml}^{-1}\right)$ at irradiation intensity of (a) $1 \mathrm{~mW} \cdot \mathrm{cm}^{-2}$, (b) $4 \mathrm{~mW} \cdot \mathrm{cm}^{-2}$, (c) $8 \mathrm{~mW} \cdot \mathrm{cm}^{-2}$. [CP2Ns-TAT] $=5.0 \mu \mathrm{g} \cdot \mathrm{mL}^{-1}$. The error bars show the standard deviation of three independent experiments. 

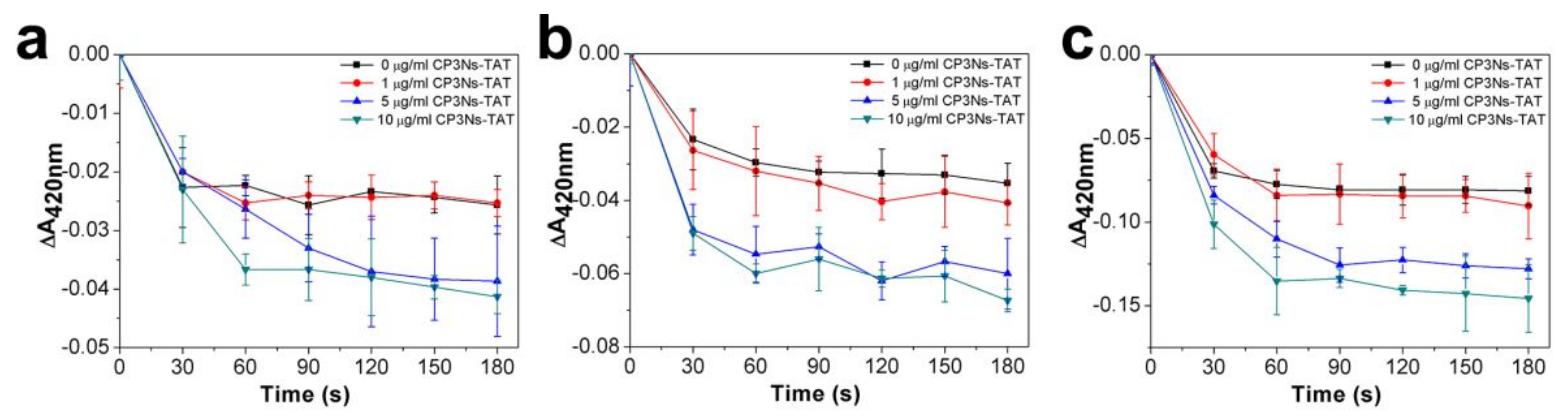

Figure S11. Measurement of photoreduction reaction by $\mathrm{K}_{3}\left[\mathrm{Fe}(\mathrm{CN})_{6}\right]$. Absorption of $R$. palustris and $R$. palustris with different concentrations of CP3Ns-TAT $\left(1.0,5.0,10.0 \mu \mathrm{g} \cdot \mathrm{ml}^{-1}\right)$ at irradiation intensity of (a) $1 \mathrm{~mW} \cdot \mathrm{cm}^{-2}$, (b) $4 \mathrm{~mW} \cdot \mathrm{cm}^{-2}$, (c) $8 \mathrm{~mW} \cdot \mathrm{cm}^{-2}$. [CP3Ns-TAT] $=5.0 \mu \mathrm{g} \cdot \mathrm{mL}^{-1}$. The error bars show the standard deviation of three independent experiments.

Table S2. Photosynthetic activity parameters of R. Palustris and R. palustris/CPNs-TAT measured by pulse amplitude modulation (PAM) after light irradiation for $3 \mathrm{~min}\left(4 \mathrm{~mW} \cdot \mathrm{cm}^{-2}\right)$. Fs, Fm', Fo', and Fv' $\left(\mathrm{Fv}^{\prime}=\mathrm{Fm}^{\prime}-\mathrm{Fo}^{\prime}\right)$ represent steady, maximum, minimum and variable state fluorescence intensity in the light-adapted state respectively. Fv'/Fm' represents the antenna conversion efficiency and ФPS represents photosystem operating efficiency. ETR is electron transport rate. [CPNs-TAT] $=5.0 \mu \mathrm{g} \cdot \mathrm{mL}^{-1}$. All the experiments are repeated for three times.

\begin{tabular}{|c|c|c|c|c|c|c|c|}
\hline & Fs & Fm' & Fo' & Fv' & Fv'/Fm' & Ф PS & ETR \\
\hline control & $\begin{array}{l}274.00 \pm \\
18.19\end{array}$ & $\begin{array}{l}487.33 \pm \\
11.60\end{array}$ & $\begin{array}{l}234.00 \pm \\
20.52\end{array}$ & $\begin{array}{r}253.33 \\
\pm 9.01\end{array}$ & $\begin{array}{ll}0.52 & \pm \\
0.03 & \end{array}$ & $\begin{array}{ll}0.44 & \pm \\
0.03 & \end{array}$ & $\begin{array}{ll}36.80 & \pm \\
2.19 & \end{array}$ \\
\hline $\begin{array}{l}R . \\
\text { palustris/CP1Ns- } \\
\text { TAT }\end{array}$ & $\begin{array}{l}173.00 \pm \\
11.53\end{array}$ & $\begin{array}{l}384.33 \pm \\
28.88\end{array}$ & $\begin{array}{l}140.67 \pm \\
17.04\end{array}$ & $\begin{array}{c}243.67 \\
\pm 15.04\end{array}$ & $\begin{array}{ll}0.63 & \pm \\
0.02 & \end{array}$ & $\begin{array}{ll}0.55 & \pm \\
0.01 & \end{array}$ & $\begin{array}{ll}46.17 \quad \pm \\
0.73 & \end{array}$ \\
\hline $\begin{array}{l}R . \\
\text { palustris/CP2Ns- } \\
\text { TAT }\end{array}$ & $\begin{array}{l}175.00 \pm \\
7.94\end{array}$ & $\begin{array}{l}375.00 \pm \\
13.89\end{array}$ & $\begin{array}{l}142.67 \pm \\
21.51\end{array}$ & $\begin{array}{c}232.33 \\
\pm 28.73\end{array}$ & $\begin{array}{ll}0.62 & \pm \\
0.06 & \end{array}$ & $\begin{array}{ll}0.53 & \pm \\
0.03\end{array}$ & $\begin{array}{l}44.75 \quad \pm \\
2.70\end{array}$ \\
\hline $\begin{array}{l}R . \\
\text { palustris/CP3Ns- } \\
\text { TAT }\end{array}$ & $\begin{array}{l}177.67 \pm \\
26.01\end{array}$ & $\begin{array}{l}395.67 \pm \\
30.01\end{array}$ & $\begin{array}{l}157.33 \pm \\
26.63\end{array}$ & $\begin{array}{c}238.33 \\
\pm 3.511\end{array}$ & $\begin{array}{ll}0.60 \quad \pm \\
0.04\end{array}$ & $\begin{array}{ll}0.55 & \pm \\
0.03 & \end{array}$ & $\begin{array}{ll}46.42 \quad \pm \\
2.77 & \end{array}$ \\
\hline
\end{tabular}

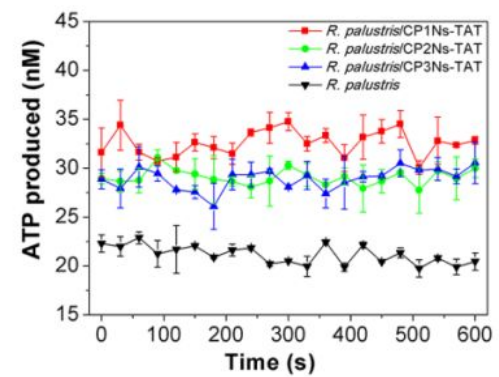


Figure S12. Time-dependent ATP synthesis of $R$. palustris and R. palustris/CPNs-TAT after irradiation for $3 \mathrm{~min}$. Irradiation intensity is $4 \mathrm{~mW} \cdot \mathrm{cm}^{-2}$. [CPNs-TAT] $=5.0 \mu \mathrm{g} \cdot \mathrm{mL}^{-1}$. The error bars show the standard deviation of three independent experiments.
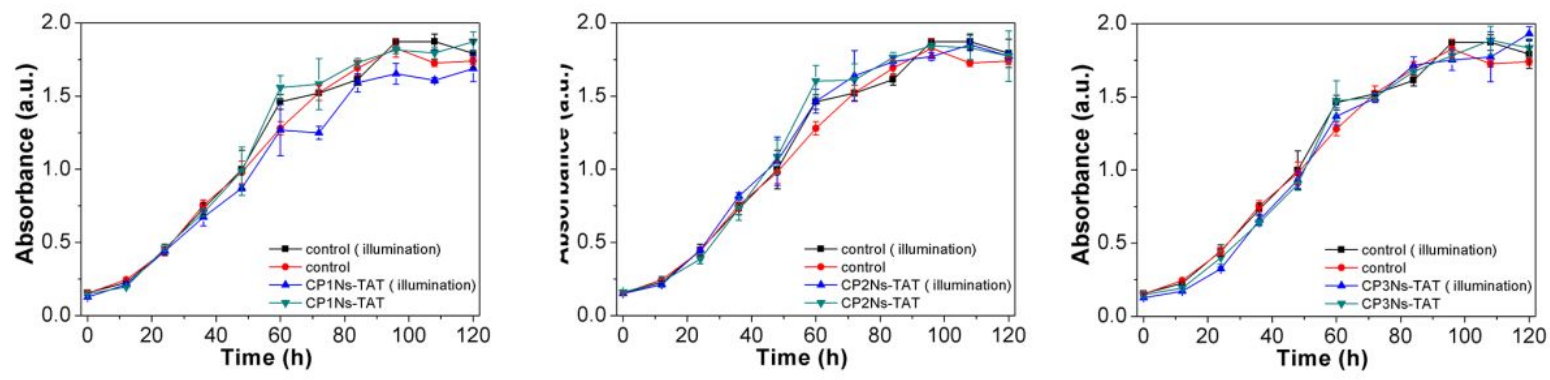

Figure S13. Growth curves of $R$. palustris and $R$. palustris/CPNs-TAT with and without illumination. Irradiation intensity is $4 \mathrm{~mW} \cdot \mathrm{cm}^{-2}$. [CPNs-TAT] $=5.0 \mu \mathrm{g} \cdot \mathrm{mL}^{-1}$. The error bars show the standard deviation of three independent experiments.

\section{REFERENCES}

1. Feng, G.; Tay, C. Y.; Chui, Q. X.; Liu, R.; Tomczak, N.; Liu, J.; Tang, B. Z.; Leong, D. T.; Liu, B., Ultrabright organic dots with aggregation-induced emission characteristics for cell tracking. Biomaterials 2014, 35 (30), 8669-8677.

2. Feng, L. H.; Liu, L. B.; Lv, F. T.; Bazan, G. C.; Wang, S., Preparation and Biofunctionalization of Multicolor Conjugated Polymer Nanoparticles for Imaging and Detection of Tumor Cells. Adv. Mater. 2014, 26 (23), 3926-3930.

3. Kamal, N.; Sabaratnam, V.; Abdullah, N.; Ho, A. S. H.; Teo, S. H.; Lee, H. B., Light-activated Cytotoxic Compounds from Malaysian Microorganisms for Photodynamic Therapy of Cancer. A. Van. Leeuw. J. Microb. 2009, 95 (2), 179-188.

4. Muzziotti, D.; Adessi, A.; Faraloni, C.; Torzillo, G.; Philippis, R. D., Acclimation Strategy of Rhodopseudomonas palustris to High Light Irradiance. Microbiol. Res. 2017, 197, 49-55. 